\title{
Effect of a new cross-linked hyaluronan gel on the staple line after sleeve gastrectomy in a rat model $^{1}$
}

\begin{abstract}
Nurullah Bülbüller', Barış Rafet Karakaş", Hülya Tosun Yıldırım"', Muhittin Yaprakv, Veli Vuralv, Sadıka Halide Akbaş ${ }^{\mathrm{VI}}$, Arzu KaravelivII, Cem Sezer ${ }^{\mathrm{VIII}}$

'Full Professor, Department of General Surgery, Faculty of Medicine, Akdeniz University, Antalya, Turkey. Conception and design of the study; acquisition, analysis and interpretation of data; manuscript preparation; critical revision.

"Associate Professor, Department of General Surgery, Antalya Training and Research Hospital, Health Sciences University, Antalya, Turkey. Conception and design of the study; acquisition, analysis and interpretation of data; manuscript preparation; critical revision.

'I'MD, Department of Pathology, Antalya Training and Research Hospital, Health Sciences University, Antalya, Turkey. Acquisition of data, manuscript preparation.

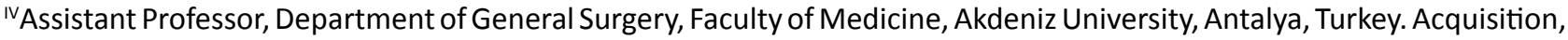
analysis and interpretation of data; manuscript preparation.

VMD, Department of General Surgery, Faculty of Medicine, Akdeniz University, Antalya, Turkey. Conception of the study, acquisition of data, manuscript preparation.

V'Full Professor, Department of Biochemistry, Faculty of Medicine, Akdeniz University, Antalya, Turkey. Acquisition, analysis and interpretation of data; manuscript preparation.

VIIMD, Department of Anesthesiology and Reanimation, Antalya Training and Research Hospital, Health Sciences University, Antalya, Turkey. Conception of the study, acquisition of data, manuscript preparation.

VIIIAssociate Professor, Department of Pathology, Antalya Training and Research Hospital, Health Sciences University, Antalya, Turkey. Conception and design of the study, analysis and interpretation of data, manuscript preparation, critical revision.
\end{abstract}

\begin{abstract}
Purpose: To evaluate the effect of a new cross-linked hyaluronan (NCHA) gel on healing of the staple line in an experimental sleeve gastrectomy.

Methods: Eighteen rats were randomly divided into three groups. The control group $(n=6)$ received no medication. In the saline group $(n=6)$ and NCHA gel group $(n=6)$, saline and NCHA gel were respectively administered onto the staple line and intraperitoneally into the abdominal cavity after the standard stapling procedure.

Results: The fibroblast activity and collagen deposition were significantly higher in the NCHA gel group than in the control group $(p=0.00, p=0.017)$ and saline group $(p=0.004, p=$ 0.015). The tissue hydroxyproline protein level was significantly higher in the NCHA gel group than in the control group ( $p=0.041)$. Adhesion formation was significantly lower in the NCHA gel group than in the control and saline groups $(p=0.015, p=0.041)$.

Conclusions: New cross-linked hyaluronan gel could be an effective approach to improve staple line wound healing and prevent potential leakage after sleeve gastrectomy. Moreover, NCHA gel helps to prevent adhesion formation without compromising healing of the staple line.
\end{abstract}

Key words: Tissue Adhesions. Wound Healing. Bariatric Surgery. Gastrectomy. Hyaluronan Gel. Rats. 


\section{Introduction}

The significantly increased mortality rate in patients with obesity contributes to the development of diseases such as cardiovascular and type II diabetes. This is an urgent public health problem. Bariatric surgical procedures are the most effective treatments for longterm weight loss ${ }^{1}$. Vertical sleeve gastrectomy restricts the stomach volume to reduce the level of ghrelin and effectively achieve weight loss. More recently, sleeve gastrectomy has been considered an effective and low-risk bariatric solution to the increasingly severe obesity problem².

Sleeve gastrectomy complications associated with the staple line are one of the major challenges facing general surgeons. Complications such as leakage at the staple line often require surgical intervention and result in a prolonged hospital stay and significant increase in the financial burden. Several different techniques have been adopted to strengthen the staple line, such as reducing bleeding and/or using glycolide-trimethylene carbonate copolymer, bovine pericardial strips, fibrin glue, hemostatic agents, and protein-rich plasma $^{3-6}$.

Hyaluronan is a non-sulfated
glycosaminoglycan containing recurrent disaccharide units (a-1,4-D- glucuronic acid and $\mathrm{b}-1,3-\mathrm{N}$-acetyl-D-glucosamine). As a major extracellular matrix (ECM) building block, hyaluronan has unique physiochemical properties such as marked biological function in all connective tissues and enhancement of wound healing 7 . Tissue repair is a complex function of hyaluronan and cannot be based on only one of its many features. Based on these unique physiochemical properties of hyaluronan, many products have been developed for tissue repair, anti-adhesion, tissue implants, and moisturizers. Many studies have shown beneficial results with respect to wound healing after exogenous hyaluronan application, including in patients with skin damage, chronic venous leg ulcers, tympanic membrane perforation, and pelviureteral anastomoses ${ }^{8-11}$. Hyaluronan is used to prevent postoperative adhesions because it creates a physiological barrier between the healing tissue and other tissue surfaces during peritoneal reepithelialization ${ }^{12}$. Moreover, Lan et $a{ }^{13}{ }^{13}$ reported that hyaluronan suppressed colonization, growth, and metastasis of a gastric cancer cell line in the peritoneal cavity of a mouse model.

The aim of our study was to evaluate the efficacy of a new cross-linked hyaluronan (NCHA) gel on staple line healing in an experimental sleeve gastrectomy model with rats. To the best of our knowledge, it is the first study to investigate the influence of hyaluronic acid in sleeve gastrectomy.

\section{Methods}

The procedures were reviewed and approved by the Akdeniz University Local Committee on Animal Research Ethics (approval number/date 49/06.05.2016). This study conformed to the Guidelines for the Care and Use of Laboratory Animals as published by the US National Institutes of Health (NIH Publication No. 85-23, revised 1985).

Eighteen female Sprague-Dawley rats at 3 to 4 months of age and weighing 300 to $400 \mathrm{~g}$ were supplied by the Experimental Animal Care and Production Unit of Akdeniz University. The animals were fasted for $18 \mathrm{~h}$ before the procedures, with free access to water.

All rats were randomly divided into three experimental groups: Control group $(n=6)$ : standard sleeve gastrectomy was performed. Saline group $(n=6)$ : upon completion of standard sleeve gastrectomy, $2 \mathrm{ml}$ of physiological saline (Pro-flex 0.9\%, Çetinkaya Illaç, Bolu, Turkey) was applied; half of the physiological saline was administered 
over the staple line, and the remaining half was applied to the bottom of the abdominal cavity. NCHA gel group $(n=6)$ : upon completion of standard sleeve gastrectomy, the NCHA gel (HyaRegen gel; BioRegen Biomedical,

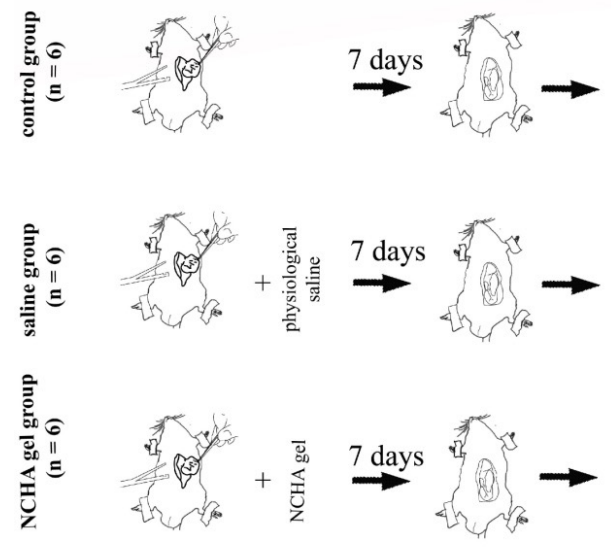

Figure 1 - Schematic drawing of experimental design.

\section{Surgical procedure}

Anesthesia was achieved by intraperitoneal administration of ketamine (75-100 mg/kg) (Alfamine 10\%; Alfasan International B.V., Woerden, Holland) and xylazine hydrochloride $(10 \mathrm{mg} / \mathrm{kg}$ ) (Alfazyne 2\%; Alfasan International B.V.). After shaving the operation site on the abdominal wall and disinfecting the skin with povidone-iodine (Poviiodeks 10\%; Kim-Pa, Istanbul, Turkey), a $4 \mathrm{~cm}$ midline abdominal incision was made. The stomach was released by dissection and covered with gauze moistened with physiological saline. The stomach was released from the abdomen, and approximately $70 \%$ to $80 \%$ of the fundus between the esophagus and pylorus was resected using a stapler (Echelon Flex 45 Endopath; Johnson \& Johnson, Guaynabo, Puerto Rico, USA) and staples (six rows, 2.5 to $1.0 \mathrm{~mm}$, ECR45W white reloads; Johnson \& Johnson) (Figure 2a, b).

The abdominal cavity was rinsed with
Changzhou, China) was applied at $2.0 \mathrm{ml} / \mathrm{kg}$; half of the gel was administered over the staple line, and the remaining half was applied to the bottom of the abdominal cavity (Figure 1 ).

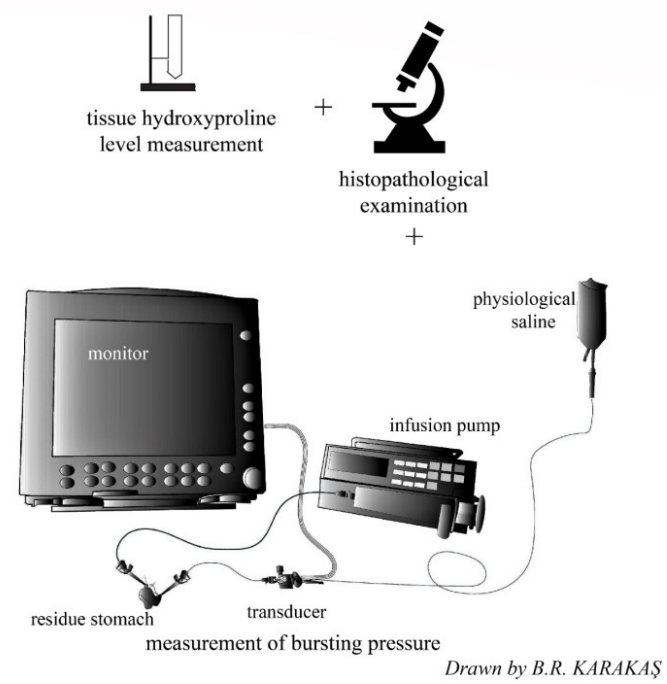

normal saline. Correspondent treatment was applied separately for the saline and NCHA groups as described above. The abdomen was closed with continuous 3-0 polyglycolic acid suture (Pegesorb ${ }^{\circ}$; Doğsan, Istanbul, Turkey). All surgical procedures were performed by two surgeons (B.R.K., V.V.). On the first postoperative day, the rats were given only water and then were given standard laboratory chow. On the 7th postoperative day, re-laparotomy was performed for analytical procedures under the above-described anesthesia protocol. Adhesions between the organs and the wall were separated. The adhesions were scored according to the method as previously described: grade 0 , no adhesions; grade 1, filmy adhesions that spontaneously separate; grade 2, firm adhesions that separate by traction; and grade 3, dense adhesions requiring sharp dissection ${ }^{14}$. The residual stomach was resected at the level of the esophagus and pylorus. Burst pressure was measured to evaluate the staple line in vitro 
(Figure 1), (Figure 2c, d). The healing staple line was removed for tissue hydroxyproline level measurement and histopathological examination (Figure 1). All rats were killed by cardiac exsanguination under deep anesthesia at the end of the experiment.

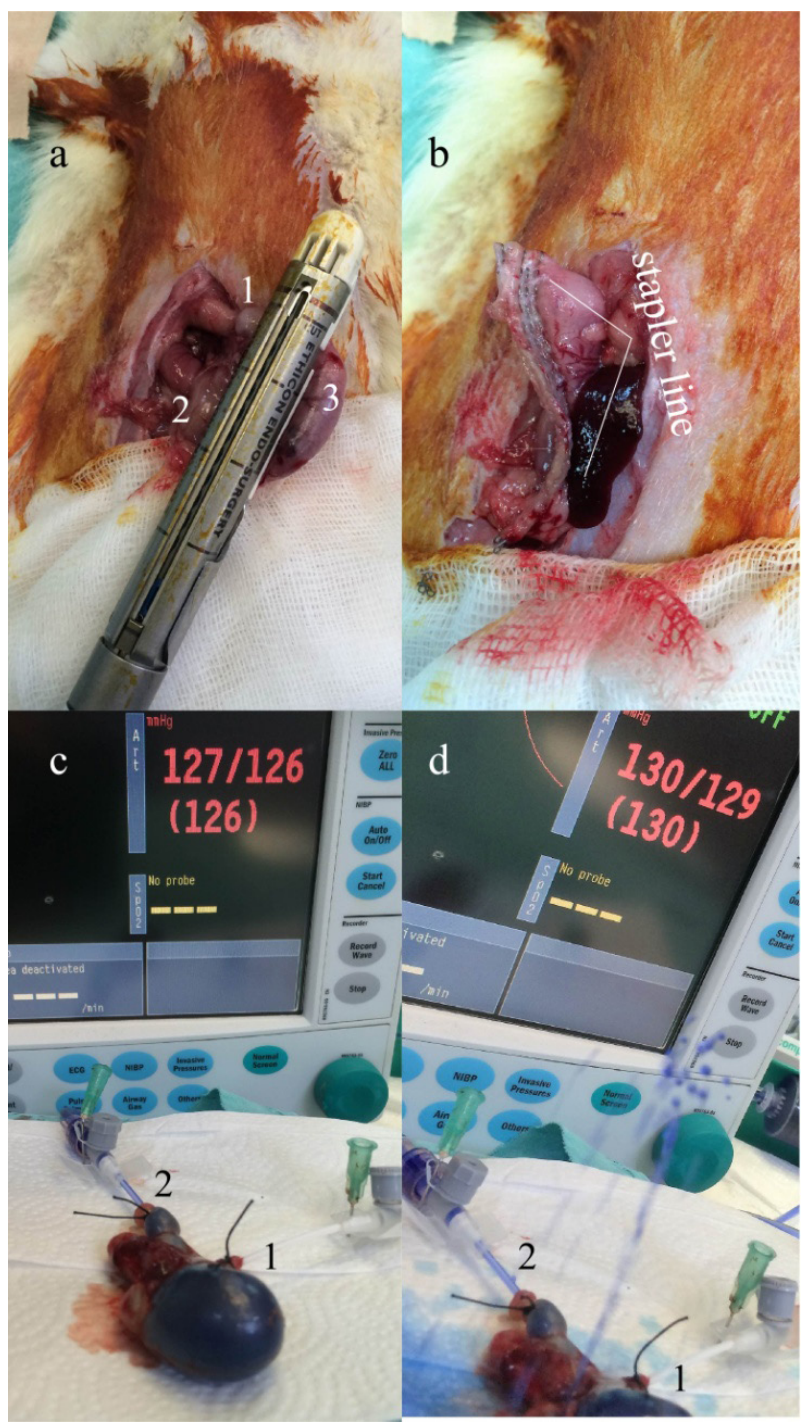

Figure 2 - Pictures of the sleeve gastrectomy procedure and measurement of the burst pressure. (a) Closing the stapler just before firing. (b) View of the staple line after sleeve gastrectomy. (c) Infusion of the methylene blue solution into residue stomach just before leaking. (d) View of leakage of the methylene blue solution from the staple line.

(1) Esophagus. (2) Pylorus. (3) Gastric fundus.

\section{Measurement of bursting pressure}

The residual stomach was resected at the level of the esophagus and pylorus. A 16-gauge plastic angiocatheter was advanced from the open end to the proximal (esophagus) and distal (pylorus) lumen. When the ends of the catheters were palpable in the residual stomach, the catheters were attached in a watertight fashion with 2-0 silk suture. The catheters were fixed to the operation table so that they could not move during the measurement. The proximal catheter connected to the infusion pump (Perfusor Compact; B. Braun ${ }^{\circ}$, Melsungen, Germany) with fixed-length tubing. A bedside pressure monitor (Datex-Ohmeda S/5; GE Healthcare, Little Chalfont, UK) was used to connect the distal catheter with the pressure transducer (Monitoring Kit, Transpac IV; Abbott Critical Care Systems, Abbott, Ireland) (Figure 1). Colored liquid (methylene blue solution) was infused into the infusion pump via a $50-\mathrm{ml}$ syringe at a constant rate of $2 \mathrm{ml} / \mathrm{s}$ until the methylene blue solution was observed leaking from the staple line. When a sudden pressure drop was seen and leakage of the methylene blue solution from the staple line was noted, it was recorded as the burst pressure for the given sample (Figure 2c, d). All infusion procedures and pressure measurements were performed by the same person (A.K.) without knowledge of the rats' group assignments. The systems were calibrated to zero before each measurement.

\section{Tissue hydroxyproline levels}

Tissue specimens were stored at $-80^{\circ} \mathrm{C}$ after weighing. At the time of analysis, the samples were dissolved and homogenized using a sonicator. Tissuehydroxyprolinemeasurement was performed with a commercial kit using the colorimetric method (Rat Hydroxyproline, Cat. No: CSB-E08838r; Cusabio Biotech Co., Ltd.). 
The amount of hydroxyproline in the samples was calculated using the standard curve. The results per unit wet tissue weight were given. In addition, tissue protein levels were measured with a commercial kit using the Lowry method (Modified Lowry Protein Assay Kit, PI-23240; Thermopierce). Hydroxyproline levels were compared with those obtained by ratios to tissue protein as $\mu \mathrm{cg} / \mathrm{mg}$ protein.

\section{Histopathological examination}

For histopathologic analytical evaluation, tissue specimens were fixed in $10 \%$ formalinsolutionand thenembedded in paraffin. Thin sections (5-7 $\mu \mathrm{m}$ ) were cut perpendicular to the anastomosis line and stained with hematoxylin and eosin and Masson's trichrome stain. Under a light microscope, a single pathologist who was blinded to the treatment method of the samples histopathologically graded the staple line according to the Ehrlich and Hunt numerical scale as modified by Phillips et al. ${ }^{15}$. Inflammatory cell infiltration, fibroblastic activity, neoangiogenesis, and collagen deposition were graded from 0 to 4 as follows: 0 , no evidence; 1 , occasional evidence; 2, light scattering; 3, abundant evidence; and 4 , confluent cells or fibers. The characteristic photographs of the different grades are shown in Figure 3a, b.
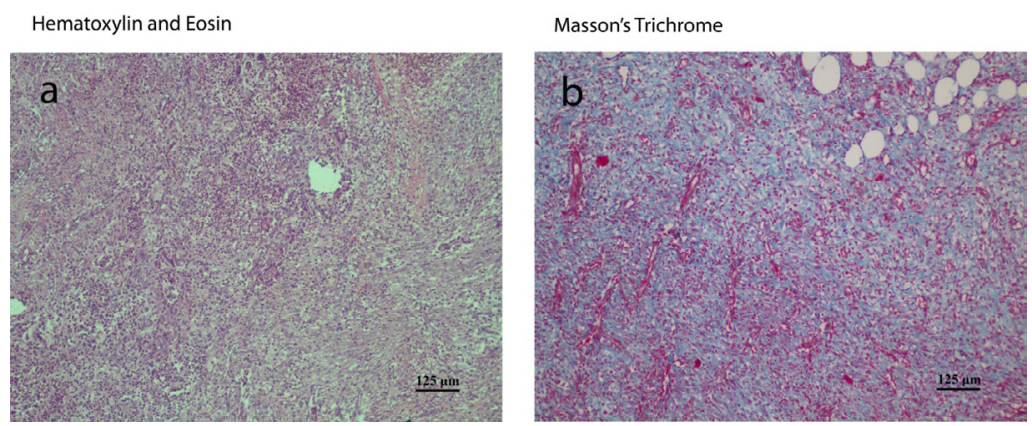

Figure 3 - Microscopic appearance of anastomosis site in the (a) control group and (b) NCHA gel group. (a) Neutrophil-rich inflammation on the anastomosis line (the section stained with hematoxylin and eosin, original magnification $\times 100$, scale bars: $125 \mu \mathrm{m}$ ). (b) Mild fibrosis on the anastomosis line (the section stained with Masson's trichrome, original magnification $\times 100$, scale bars: $125 \mu \mathrm{m}$ ).

\section{Statistical analysis}

Data were analyzed using Statistical Package for Social Sciences 19.0 (IBM Corp., Armonk, NY, USA). All values are given as the median (minimum-maximum). Kruskal-Wallis variance analysis and the Mann-Whitney U-test were used to compare the groups. A $p$ value of $<0.05$ was considered statistically significant.

\section{- Results}

The adhesion score, burst pressure, histopathological score, and tissue hydroxyproline level are summarized in Table 1 and shown in Figures 4 to 7 for each group.

Significantly lower adhesion scores were found in the NCHA gel group than in the control and saline groups ( $p=0.015, p=0.041)$ (Figure 4). During the burst measurement, all leaks were monitored on the staple recovery line. No significant difference in burst pressures was identified among the groups (Figure 5). 
Table 1 - Adhesion scores, burst pressure, tissue hydroxyproline level, and histopathological grading in the three study groups

\begin{tabular}{llll}
\hline Parameters & Control Group & Saline Group & NCHA gel Group \\
\hline Adhesion Scores & $2.5(2-3)$ & $2(2-3)$ & $1(1-2) * q$ \\
Bursting Pressure (mm Hg) & $37(22-154)$ & $118(35-157)$ & $100(71-130)$ \\
$\begin{array}{l}\text { Tissue Hydroxyproline Level } \\
\text { Hydroxyproline/Protein }\end{array}$ & 44.49 & 166.04 & 240.06 \\
$\begin{array}{l}\text { (mcg/Mg Protein) } \\
\text { Histopathological Grading }\end{array}$ & $(3.20-216.03)$ & $(11.83-253.70)$ & $(56.52-500.52)$ \\
$\quad$ & & \\
$\quad$ Inflammatory Cell Infiltration \\
$\quad$ Neoangiogenesis & $4(3-4)$ & $3(2-4)$ & $2(1-2) \Delta$ \\
$\quad$ Fibroblast Activity & $3(2-4)$ & $2.5(2-3)$ & $3(3-4)$ \\
$\quad$ Collagen Deposition & $2.5(2-3)$ & $2.5(2-3)$ & $4(3-4) \square$ \\
\hline
\end{tabular}

The values represent the median (min-max). Significance was defined as $p<0.05$. Differences between the two groups were compared using the Mann-Whitney U-test. $* p=0.015$ compared with control group. $\uparrow p=0.041$ compared with saline group. $\boldsymbol{\Delta} p$ $=0.041$ compared with control group. $\Delta p=0.002$ compared with control group. $\square p=0.009$ compared with saline group. $\square p=0.004$ compared with control group. $\bullet p=0.004$ compared with saline group. op $=0.017$ compared with control group. $\bullet p=0.015$ compared with saline group.

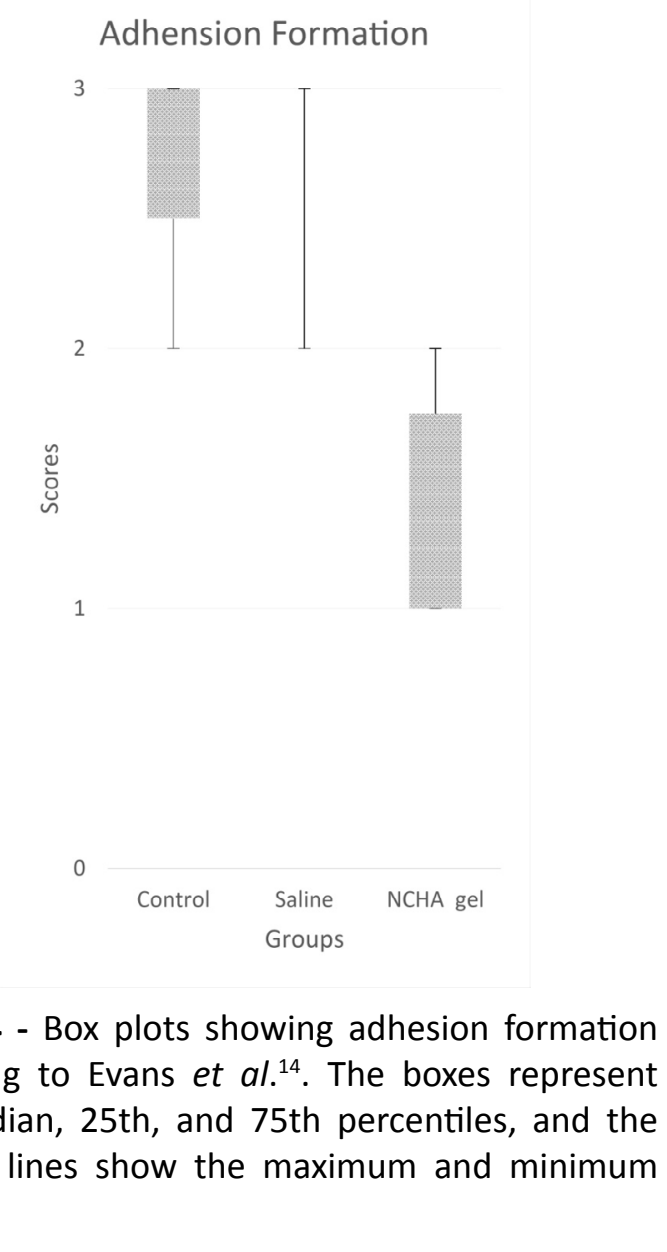

Figure 4 - Box plots showing adhesion formation according to Evans et al. ${ }^{14}$. The boxes represent the median, 25th, and 75th percentiles, and the whisker lines show the maximum and minimum levels.

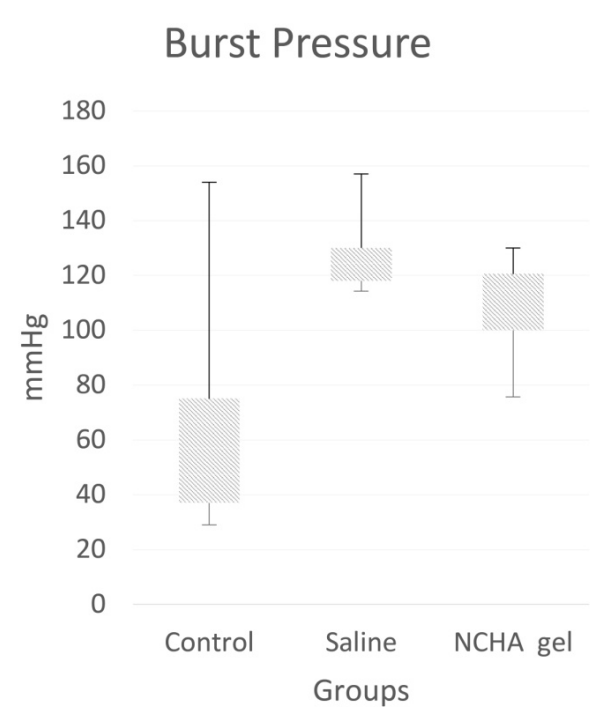

Figure 5 - Box plots showing burst pressures $(\mathrm{mmHg})$. The boxes represent the median, 25th, and 75th percentiles, and the whisker lines show the maximum and minimum levels.

Inflammatory cell infiltration was significantly lower in the NCHA gel group than in the control and saline groups $(p=0.002, p$ 
$=0.009)$. The fibroblast activity and collagen deposition were significantly higher in the NCHA gel group than in the control group $(p=$ $0.004, p=0.004)$ and saline group $(p=0.017$, $p=0.015)$ (Figure 6). The tissue hydroxide protein level was significantly higher in the $\mathrm{NCHA}$ gel group than in the control group $(\mathrm{p}=$ 0.041) (Figure 7).

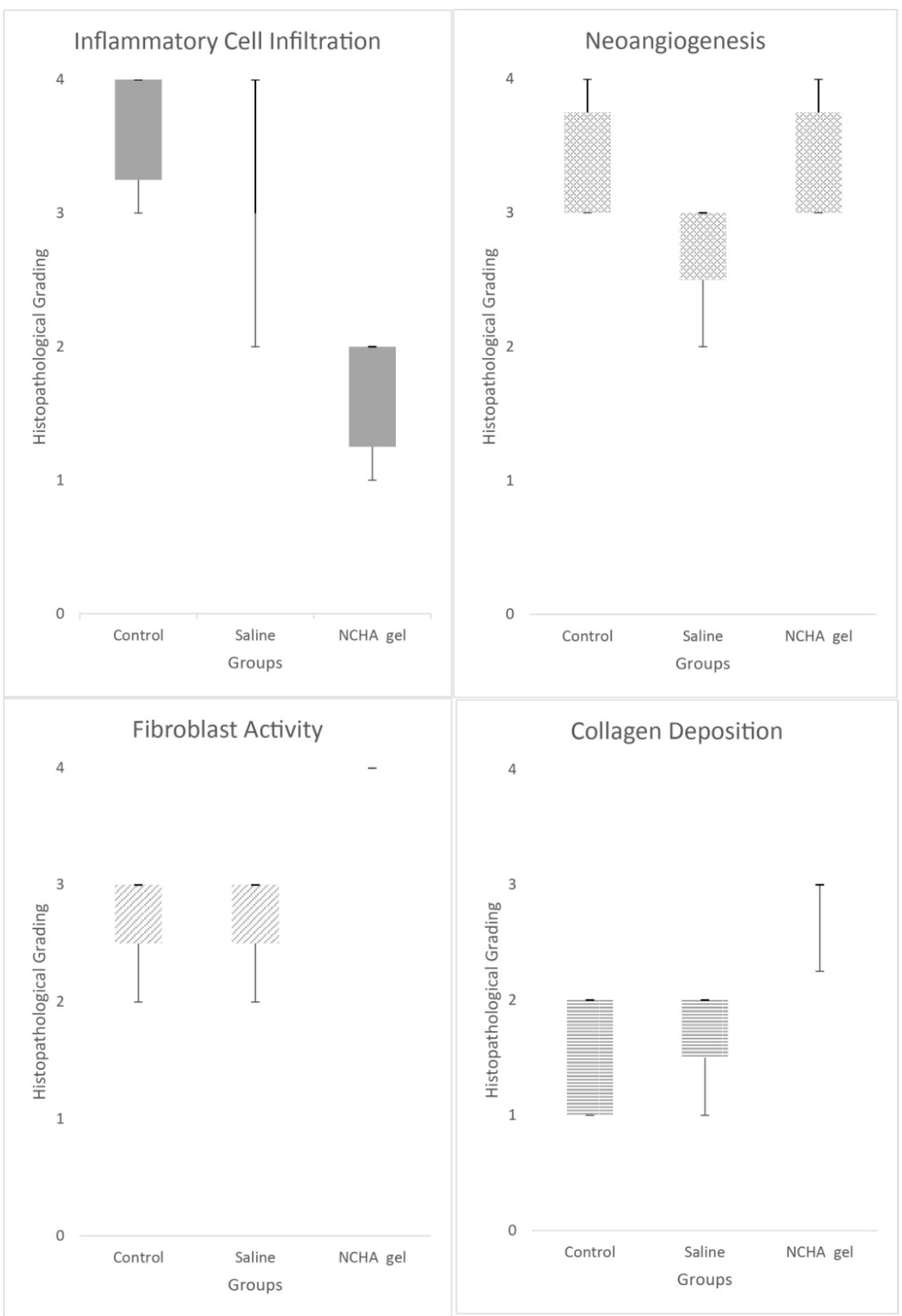

Figure 6 - The box plots showing the changes in the histopathological grade. The boxes represent the median, 25th, and 75th percentiles, and the whisker lines show the maximum and minimum levels. 


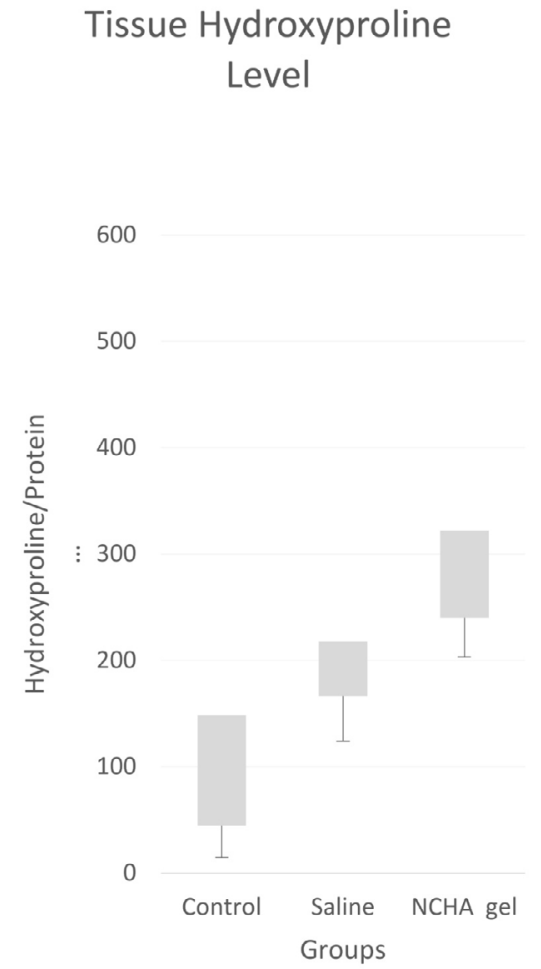

Figure 7 - Box plots showing the tissue hydroxyproline levels [hydroxyproline/protein ( $\mu \mathrm{cg} / \mathrm{mg}$ protein)]. The boxes represent the median, 25th, and 75th percentiles, and the whisker lines show the maximum and minimum levels.

\section{- Discussion}

Morbid obesity is a serious public health problem, and the most effective treatment is bariatric surgery. Sleeve gastrectomy is one of the most accepted methods among bariatric surgical procedures. One of the most consequential complications of sleeve gastrectomy is leakage. Leakage from the staple line is the second most frequent cause of death associated with bariatric surgery ${ }^{16}$. The present study is the first to show that NCHA gel administration as a reinforcement agent increases crucial wound-healing parameters such as fibroblastic activity, neoangiogenesis, collagen deposition, and the tissue hydroxide protein level and reduces inflammatory reactions such as cell infiltration in the staple line after sleeve gastrectomy in rats.

Reinforcement of the staple line with buttress material is among the technical recommendations for preventing this type of leakage. Gentileschi et al. found no differences among oversewing, buttressed transection with polyglycolic acid and trimethylene carbonate, and staple-line roofing with a gelatin fibrin matrix ${ }^{17}$. Wang et al. ${ }^{18}$ showed that oversewing of the staple line increased the operation time, but no evidence demonstrated that it reduced leakage. Al Hajj and Haddad reported that staple-line buttressing with bovine pericardium reduced staple line leakage ${ }^{4}$. Gagner and Buchwald ${ }^{19}$ compared no reinforcement, oversewing, nonabsorbable bovine pericardial strips, and absorbable polymer membrane application and reported that the most successful method among these procedures was absorbable polymer membrane application. Karakoyun et al. ${ }^{20}$ reported that oversewing with a continuous suture on the staple line was more successful than reinforcement of the staple line with fibrin sealant. Shikora et al. ${ }^{21}$ compared the effectiveness of different methods including oversewing, a biocompatible glycolide copolymer, bovine pericardium, and no reinforcement and found that the most successful method was buttressing with bovine pericardium. Çoşkum et al. ${ }^{22}$ used fibrin sealant for reinforcement of the staple line in their study and found no leakage. Sepulveda et al. ${ }^{23}$ reported that the staple line was strengthened with imbricated oversewing in their study and reported no leakage. Overall, however, there is still no consensus regarding which reinforcement procedure can significantly and reliably prevent leakage from the staple line. 
There is a clinical need to identify a consistently reliable method for reinforcement of the staple line.

Ortonne et al. ${ }^{9}$ reported that hyaluronan decreased ulcer dimensions in patients with venous leg ulcers. Hellstrom et al. ${ }^{10}$ showed that hyaluronan-treated perforations closed more rapidly than did untreated perforations in a model of induced tympanic membrane perforations in rats. Yurtçu et al. ${ }^{11}$ reported that hyaluronan facilitated wound healing by increasing re-epithelialization and neovascularization in an experimental model of pelviureteral anastomosis in rabbits. Lan et $a .^{13}$ reported that hyaluronan suppressed colonization, growth, and metastasis of a gastric cancer cell line in an experimental model. Taken together, these studies indicate that hyaluronan gel is a potential reinforcement agent for the staple line by improving the tissue repair process.

Hyaluronan has been shown to support acute and chronic wound healing in many models. Hyaluronan binds to three main cell surface receptor classes: CD44, receptor for hyaluronan mediated motility (RHAMM), and intracellular adhesion molecule-1 (ICAM1). CD44 receptors play a role in hyaluronan uptake and degradation, cell-cell and cellsubstrate adhesion, and cell migration and activation. One of the major biological effects of hyaluronan when it associates with the CD44 receptor is stimulation of the ECM; it also provides localized balance of the hyaluronan level. Upregulation of the expression of several cytokines, such as interleukin $1 \beta$ (IL$1 \beta)$, tumor necrosis factor- $\alpha$, and insulin-like growth factor-1 induce several inflammatory gene expressions through a CD44-directed mechanism in macrophages; this in turn increases collagen production in endothelial cells. RHAMM is present in most mobile cells, including migrating fibroblasts and highly metastatic tumor cells, and is involved in cell locomotion. ICAM-1 is a widely distributed cell adhesion molecule in macrophages and other cells, including endothelial cells. The ICAM-1 receptor allows hyaluronan to be taken up by the cells, and destruction of the intracellular area then occurs. By binding with hyaluronan and ICAM-1, leukocyte integrins are affected by other receptors such as lymphocyte function associated-1 and macrophage antigen complex-1, potentially contributing to inflammatory activation?.

Hyaluronan plays multiple roles in healing. Although inflammation is crucial for the formation of granulation tissue, stabilization of the granulation tissue matrix is necessary by alleviating inflammation to maintain normal tissue repair. The free-radical scavenging role of hyaluronan may influence inflammatory activation. In this regard, hyaluronan provides protection against free radical and proteolytic damage in the cell and $\mathrm{ECM}^{24}$. Campo et al. ${ }^{25}$ showed that hyaluronan reduced inflammatory mediators such as tumor necrosis factor- $\alpha$, IL-1ß, IL-17, MMP-13, and inducible nitric oxide synthase, which play active roles in inflammation and cartilage destruction in an experimental arthritis mouse model. Hyaluronan is one of the main components of the ECM. It is the most important support structure of proteoglycans. It is also associated with collagen, fibrin, and other matrix molecules. Hyaluronan promotes the early tissue damage response and the formation of fibrin-rich transient matrix. Accordingly, it promotes fibroblast and endothelial cell movement to the wound area and subsequent formation of granulation tissue in the early stage of tissue repair. If the hyaluronan binds to the ECM components by its hydrophilic structure, it creates an environment that 
allows cell migration to the newly formed tissue region ${ }^{26}$.

In the present study, neutrophil infiltration was significantly lower in the NCHA gel group. Fibroblast infiltration, fibrosis formation, and the hydroxyproline level were significantly higher in the NCHA gel group. Although there were no statistically significant differences in burst pressure among the groups, the burst pressure showed a tendency to increase in the NCHA gel group compared with the control group. These results suggest that NCHA gel administration had a positive effect on tissue healing.

Wong et al. ${ }^{27}$ reported that the level of cross-link modification of hyaluronic acid is positively correlated with resistance to enzymatic degradation of substrates. NCHA is a cross-linked hyaluronan gel with high viscosity and stickiness; it can stay on the surface of abdominal organs for up to 2 weeks and therefore prevent intra-abdominal adhesions. A recent study showed that NCHA gel significantly reduced adhesion formation throughout the abdominal cavity ${ }^{12}$. Menzies and Ellis ${ }^{28}$ showed that postoperative adhesions formed in $10.4 \%$ of patients after first abdominal surgery. Postoperative adhesions may cause a life-long risk of different complications such as chronic abdominal pain, bowel obstruction, and infertility in women. Therefore, preventing postoperative adhesions in the abdominal cavity should be one of the treatment focuses of sleeve gastrectomy.

\section{Conclusions}

New cross-linked hyaluronan gel, a potent wound healing agent, can effectively improve reinforcement of the staple line of sleeve gastrectomy in rats. Moreover, the NCHA gel contributes to preventing adhesion formation without compromising healing of the staple line. All of these results have important clinical implications and relevance.

\section{- References}

1. Colquitt JL, Pickett $\mathrm{K}$, Loveman $\mathrm{E}$, Frampton GK. Surgery for weight loss in adults. Cochrane Database Syst Rev. 2014;8:CD003641. PMID: 25105982.

2. Carmichael AR, Sue-Ling HM, Johnston D. Quality of life after the Magenstrasse and Mill procedure for morbid obesity. Obes Surg. 2001;11:708. PMID: 11775568.

3. Consten EC, Gagner M, Pomp A, Inabnet WB. Decreased bleeding after laparoscopic sleeve gastrectomy with or without duodenal switch for morbid obesity using a stapled buttressed absorbable polymer membrane. Obes Surg. 2004;14:1360-6. PMID: 15603652.

4. Al Hajj GN, Haddad J. Preventing staple-line leak in sleeve gastrectomy: reinforcement with bovine pericardium vs. oversewing. Obes Surg. 2013;11:1915-21. PMID: 23975327.

5. Dapri G1, Cadière GB, Himpens J. Reinforcing the staple line during laparoscopic sleeve gastrectomy: prospective randomized clinical study comparing three different techniques. Obes Surg. 2010;4:462-7. PMID: 20012507.

6. Casella G, Soricelli E, Genco A, Ferrazza $G$, Basso $N$, Redler $A$. Use of plateletrich plasma to reinforce the staple line during laparoscopic sleeve gastrectomy: feasibility study and preliminary outcome. J Laparoendosc Adv Surg Tech A. 2015;3:2227. doi: 10.1089/lap.2014.0329.

7. Chen WY, Abatangelo G. Function of hyaluronan in wound repair. Wound Repair Regen. 1999;7:79-89. PMID: 25668681.

8. Gilchrest BA. Treatment of photodamage with topical tretinoin: an overview. J Am Acad Dermatol. 1997;3:S27-36. PMID: 9091506.

9. Ortonne JP. Comparative study of the activity of hyaluronic acid and dextranomer in the treatment of leg ulcers of venous origin. Ann Dermatol Venereol. 2001;Suppl:13-6. PMID: 11526821.

10.Hellström S, Laurent C. Hyaluronan and 
healing of tympanic membrane perforations. An experimental study. Acta Otolaryngol. 1987;442(Suppl.):54-61. PMID: 3481167.

11.Yurtçu M, Baba ZF. The effect of natrium hyaluronate applied locally for pelviureteral anastomoses. Ren Fail. 2013;1:138-42. PMID: 23157161.

12.Liu C, Lu Q, Zhang Z, Xue M, Zhang $Y$, Zhang $\mathrm{Y}$, Wang $\mathrm{H}$, Li $\mathrm{H}$, Zhou $\mathrm{Y}$, Zhang $\mathrm{Z}$, Li W; HyaRegen Adhesion Study Group. A Randomized controlled trial on the efficacy and safety of a new crosslinked hyaluronan gel in reducing adhesions after gynecologic laparoscopic surgeries. Minim Invasive Gynecol. 2015;5:853-63. PMID: 25906706.

13.Lan T, Pang J, Wu Y, Zhu M, Yao X, Wu M, Qian H, Zhang Z, Gao J, Chen Y. Cross-linked hyaluronic acid gel inhibits metastasis and growth of gastric and hepatic cancer cells: in vitro and in vivo studies. Oncotarget. 2016;40:65418-28. PMID: 27589842.

14.Evans DM, McAree K, Guyton DP, Hawkins $N$, Stakleff K. Dose dependency and wound healing aspects of the use of tissue plasminogen activator in the prevention of intra-abdominal adhesions. Am J Surg. 1993;2:229-32. PMID: 8427402.

15.Phillips JD, Kim CS, Fonkalsrud EW, Zeng $H$, Dindar $\mathrm{H}$. Effects of chroniccorticosteroids and vitamin $A$ on the healing of intestinal anastomoses. Am J Surg. 1992;163:71. PMID: 1733376.

16.lossa A, Abdelgawad M, Watkins BM, Silecchia G. Leaks after laparoscopic sleeve gastrectomy: overview of pathogenesis and risk factors. Langenbecks Arch Surg. 2016;6:757-66. PMID: 27301373.

17.Gentileschi P, Camperchioli I, D'Ugo S, Benavoli D, Gaspari AL. Staple-line reinforcement during laparoscopic sleeve gastrectomy using three different techniques: a randomized trial. Surg Endosc. 2012;9:2623-9. PMID: 22441975.

18.Wang Z, Dai X, Xie H, Feng J, Li Z, Lu Q.The efficacy of staple line reinforcement during laparoscopic sleeve gastrectomy: a metaanalysis of randomized controlled trials. Int J Surg. 2016;25:145-52. PMID: 26700201.

19.Gagner M, Buchwald JN. Comparison of laparoscopic sleeve gastrectomy leak rates in four staple-line reinforcement options: a systematic review. Surg Obes Relat Dis. 2014;10:713-24. PMID: 24745978.

20.Karakoyun R, Gündüz U, Bülbüller N, Çalış H, Habibi M, Öner O, Gülkesen H. The effects of reinforcement methods on burst pressure in resected sleeve gastrectomy specimens. J Laparoendosc Adv Surg Tech A. 2015;1:648. PMID: 25531037.

21.Shikora SA, Mahoney CB. Clinical benefit of gastric staple line reinforcement (SLR) in gastrointestinal surgery: a meta-analysis. Obes Surg. 2015;7:1133-41. PMID: 25968078.

22. Coskun $H$, Yardimci E. Effects and results of fibrin sealant use in 1000 laparoscopic sleeve gastrectomy cases. Surg Endosc. 2017;5:2174-9. PMID: 27604365.

23.Sepúlveda M, Astorga C, Hermosilla JP, Alamo $M$. Staple line reinforcement in laparoscopic sleeve gastrectomy: experience in 1023 consecutive cases. Obes Surg. 2017;6:147480. PMID: 28054296.

24.Foschi D, Castoldi L, Radaelli E, Abelli P, Calderini G, Rastrelli A, Mariscotti C, Marazzi M, Trabucchi E. Hyaluronic acid prevents oxygen free-radical damage to granulation tissue: a study in rats. Int J Tissue React. 1990;6:333-9. PMID: 1966392.

25.Campo GM1, Avenoso A, Nastasi G, Micali $A$, Prestipino $V$, Vaccaro $M$, D’Ascola $A$, Calatroni A, Campo S. Hyaluronan reduces inflammation in experimental arthritis by modulating TLR-2 and TLR-4 cartilage expression. Biochim Biophys Acta. 2011;9:1170-81. PMID: 21723389.

26. Weigel PH, Fuller GM, LeBoeuf RD. A model for the role of hyaluronic acid and fibrin in the early events during the inflammatory response and wound healing. J Theor Biol. 1986;2:219-34. PMID: 3736072.

27.Wong RS, Ashton M, Dodou K. Effect of crosslinking agent concentration on the properties of unmedicated hydrogels. Pharmaceutics. 2015;3:305-19. PMID: 26371031.

28. Menzies D, Ellis H. Intestinal obstruction from adhesions--how big is the problem? Ann R Coll Surg Engl. 1990;1:60-3. PMID: 2301905. 


\section{- Acknowledgements}

To Dr. Jizong Gao for providing helpful advice, and Angela Morben for helping us in the process of editing.

\section{Correspondence:}

Prof. Nurullah Bülbüller

Department of General Surgery, Faculty of

Medicine

Akdeniz University, 07070

Antalya Turkey

Phone: +90 24224960 00/3073

nbulbuller@yahoo.com

nbulbuller@akdeniz.edu.tr

Received: Oct 18, 2017

Review: Dec 20, 2017

Accepted: Jan 22, 2018
Conflict of interest: none

Financial source: Bilar Medikal Co.
${ }^{1}$ Research performed at Laboratory Animal Research Center, Akdeniz University, Antalya, Turkey.

